\title{
Triptolide contributes to decrease in TLR4 expression by upregulating miR-224-3p to inhibit the inflammatory reaction in diabetic nephropathy
}

\author{
Bei Sun ${ }^{1, *}$, Shaolan Hu${ }^{1, *}$, Yongmei Li $^{2}$, Endong Zhu ${ }^{1}$, Li Li ${ }^{1}$, Fei Han ${ }^{1}$, Chun-Jun Li $^{1}$ \\ and Liming Chen ${ }^{1}$ \\ ${ }^{1}$ Key Laboratory of Hormones and Development, Ministry of Health, Tianjin Key Laboratory of Metabolic Diseases, Tianjin \\ Metabolic Diseases Hospital \& Tianjin Institute of Endocrinology, Tianjin Medical University, Tianjin, China \\ 2 Department of Medical Microbiology, School of Basic Medical Sciences, Tianjin Medical University, Tianjin, China \\ * These authors have contributed equally to this work \\ Correspondence to: Liming Chen, email: xfx22081@vip.163.com \\ Chun-Jun Li, email: li_chunjun@126.com \\ Keywords: diabetic nephropathy, triptolide, miRNA, TLR4, inflammation, Pathology Se \\ Received: August 01, $2016 \quad$ Accepted: October 13, 2016 \\ ABSTRACT
}

Triptolide has been shown to have anti-inflammatory properties. miRNAs have emerged as important regulators of DN. However, the role of miRNAs in inflammation regulation during DN development is poorly understood. In this study, we investigated the effects of the association between miRNAs and triptolide on inflammation in DN. We found that triptolide significantly inhibits the inflammatory reactions of DN in rats, and miR-224-3p is selectively upregulated more than 2 fold in NRK-52E cells treated with triptolide compared to the cells without treatment. miR-224-3p overexpression exerts similar effects to those of triptolide, while miR-224-3p downregulation increases all the inflammatory reactions above. In summary, we found that triptolide attenuates the inflammatory reactions in $D N$ by upregulating miR-224-3p expression.

\section{INTRODUCTION}

Diabetic nephropathy (DN) has become an important cause of end-stage renal disease and death in diabetic patients [1.2]. Approximate $40 \%$ of patients with type 2 diabetes (T2D) will develop DN and even renal failure [3]. However, the pathogenesis of DN is complex, and inflammation theory and immune system activation have attracted the interest of serentists worldwide [4] .

TLRs represent the receptors of the innate immune system [5]. TLRs activate downstream inflammatory response, such as the NF- $\mathrm{KB}$ pathway, which initiates the acquired immune response [6]. TLR4 activation promotes tubulointerstitial inflammation and fibrosis, which deteriorated the renal function of DN [7].

Unfortunately, there are no effective treatments for DN [8-10]. In recent years, treatment of DN with traditional Chinese medicines has achieved positive results $[11,12]$. Tripterygium glycosides can promote the production of anti-inflammatory mediators in many cells. Triptolide is the most active ingredient of tripterygium glycosides [13-15]. Our previous study showed that triptolide could ameliorate tubulointerstitial fibrosis via TLR4/NF-kB [16].

miRNAs bind specific genes and facilitate mRNA cleavage or mRNA translation inhibition and thus participate in a variety of physiological and pathological processes [17]. Recent studies have shown that miRNAs correlate with DN [18-20].

We studied the mechanism underlying the antiinflammatory effects of triptolide via biochip technology in DN rats. Triptolide attenuated inflammation by upregulating miR-224-3p expression and the plasma levels of miR-224-3p were significantly lower in the patients with DN. 


\section{RESULTS}

\section{Effects of triptolide treatment on blood biochemical parameters}

The blood biochemical parameters were showed in Table 1. During the study period, the levels of blood glucose, TC and TG were significantly higher in both DN and TP-treated rats compared with the $\mathrm{NC}$ rats $(P<0.05)$. However, there were no significant differences between $\mathrm{DN}$ and TP-treated groups $(P>0.05)$, indicating that TP had no effects on blood glucose and blood lipid. In addition, the AST and ALT levels did not differ among the five groups $(P>0.05)$. Furthermore, Scr and BUN did not change in these groups by the end of the experiment $(P>0.05)$.

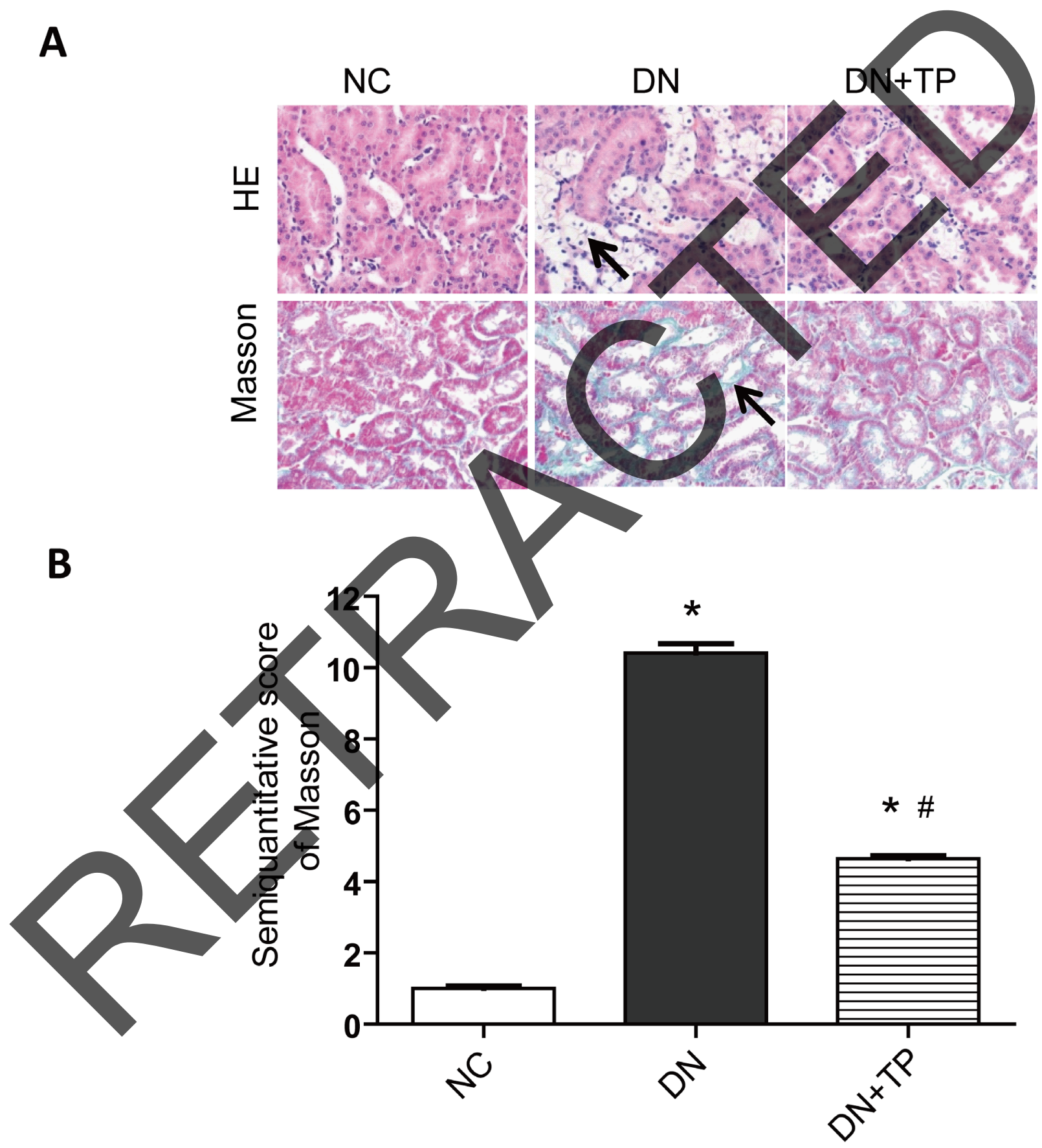

Figure 1: Pathological analysis of rat kidney tissue. A. HE staining. B. Representative Masson's staining. C. Semiquantitative tubulointerstitial fibrosis scoress. NC, normal control; DN without drug treatment; TP, triptolide treatment $(200 \mu \mathrm{g} / \mathrm{kg} \cdot \mathrm{d}) .{ }^{*} p<0.05 \mathrm{versus}$ NC group, \# $p<0.05$ versus DN group. 
A

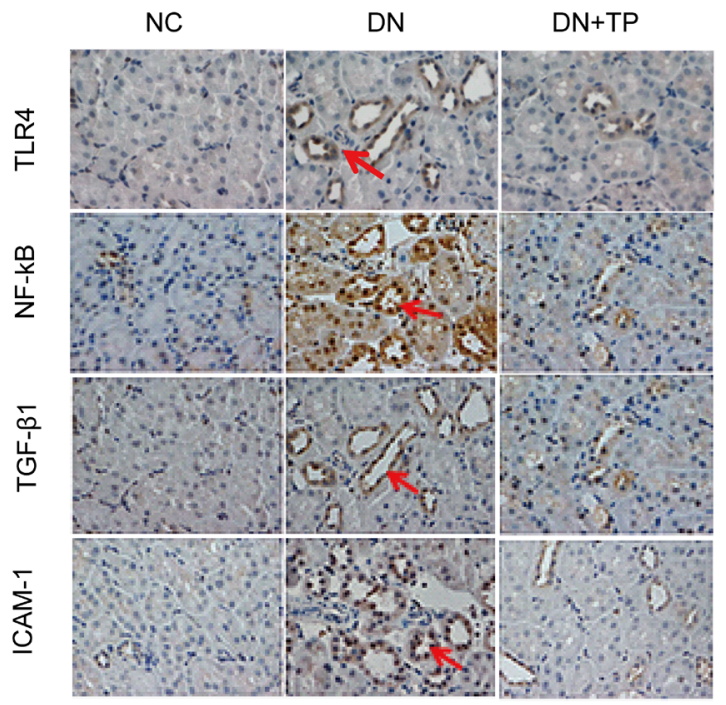

B

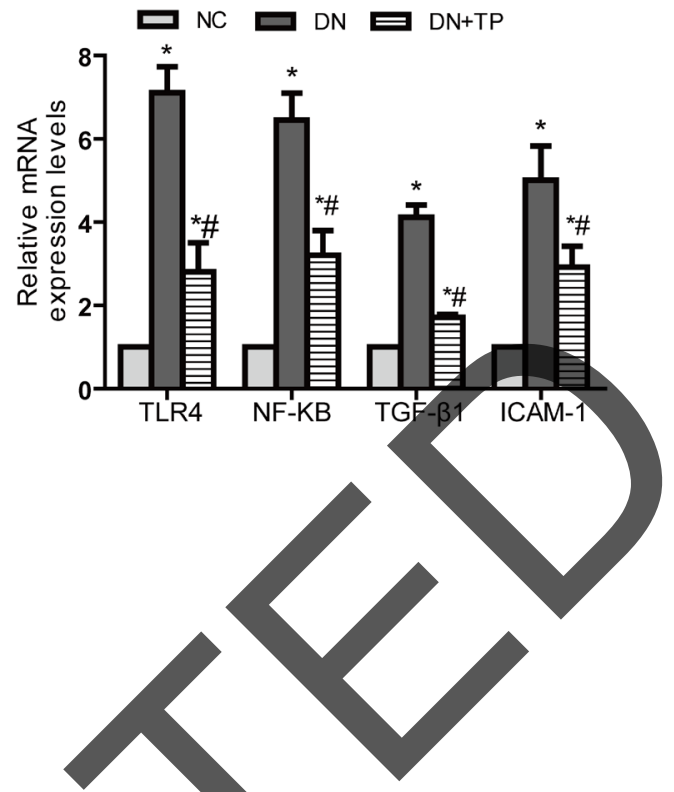

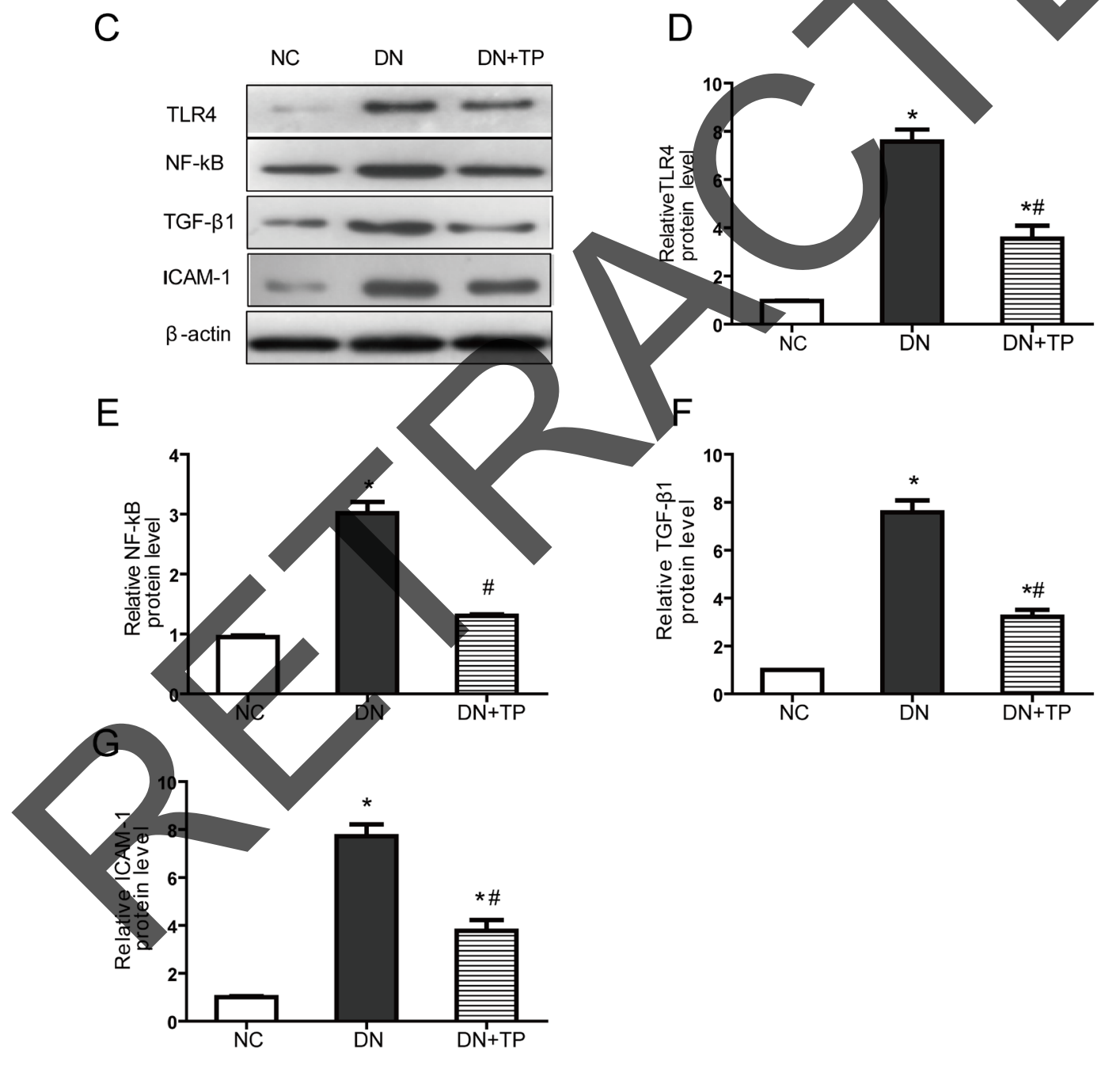

Figure 2: Triptolide improves renal inflammation in DN rats. A. Immunostaining B. The mRNA expression levels C. Representative western blotting. D.-G. Densitometric results for TLR4, NF- $\kappa$ B, TGF- $\beta 1$ and ICAM-1, as determined via western blotting. $\mathrm{NC}$, normal control; DN without drug treatment; TP, triptolide treatment $(200 \mu \mathrm{g} / \mathrm{kg} \cdot \mathrm{d}) .{ }^{*} p<0.05$ versus $\mathrm{NC}$ group, \# $p<0.05$ versus $\mathrm{DN}$ group. 


\section{Effect of triptolide on urinary protein, NAG and KW/BW}

The $24 \mathrm{~h}$ urine protein was significantly increased in the DN rats compared with that in the $\mathrm{NC}$ rats $(P<$ 0.05 ), which was attenuated after TP administration for 8 weeks $(P<0.05)$. NAG, one of the urinary tubular injury biomarkers, was significantly increased in the DN rats compared with that in the $\mathrm{NC}$ rats, but was markedly reduced by TP treatment $(P<0.05)$. The kidney weight to body weight ratio $(\mathrm{KW} / \mathrm{BW})$ was significantly higher in the DN rats compared with the $\mathrm{KW} / \mathrm{BW}$ in the $\mathrm{NC}$ rats $(P$ $<0.05$ ). By contrast, $\mathrm{KW} / \mathrm{BW}$ was significantly reduced in the TP treatment group $(P<0.05)$, but still remained significantly higher in comparison with normal control (Table 1).

A
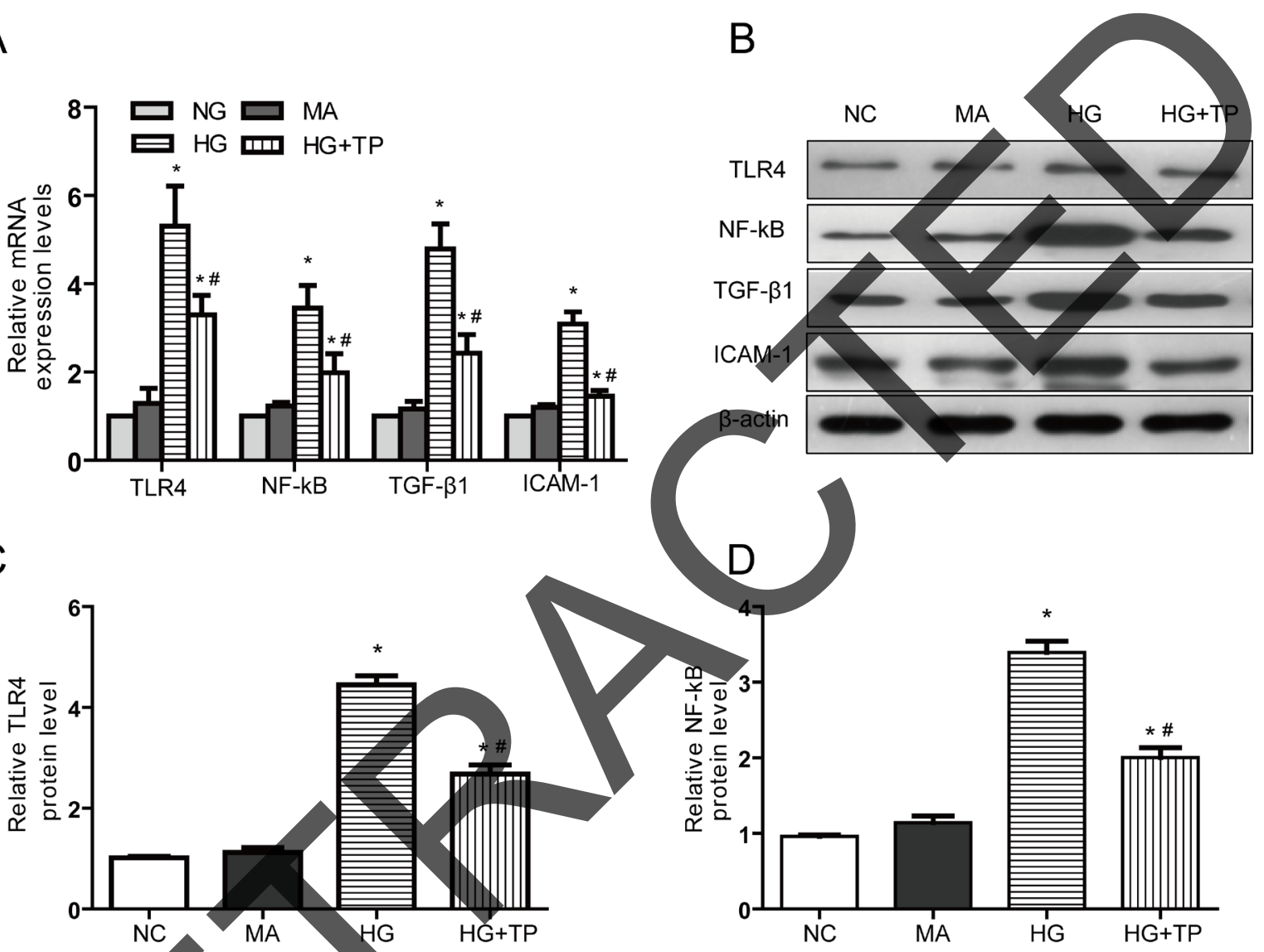

C
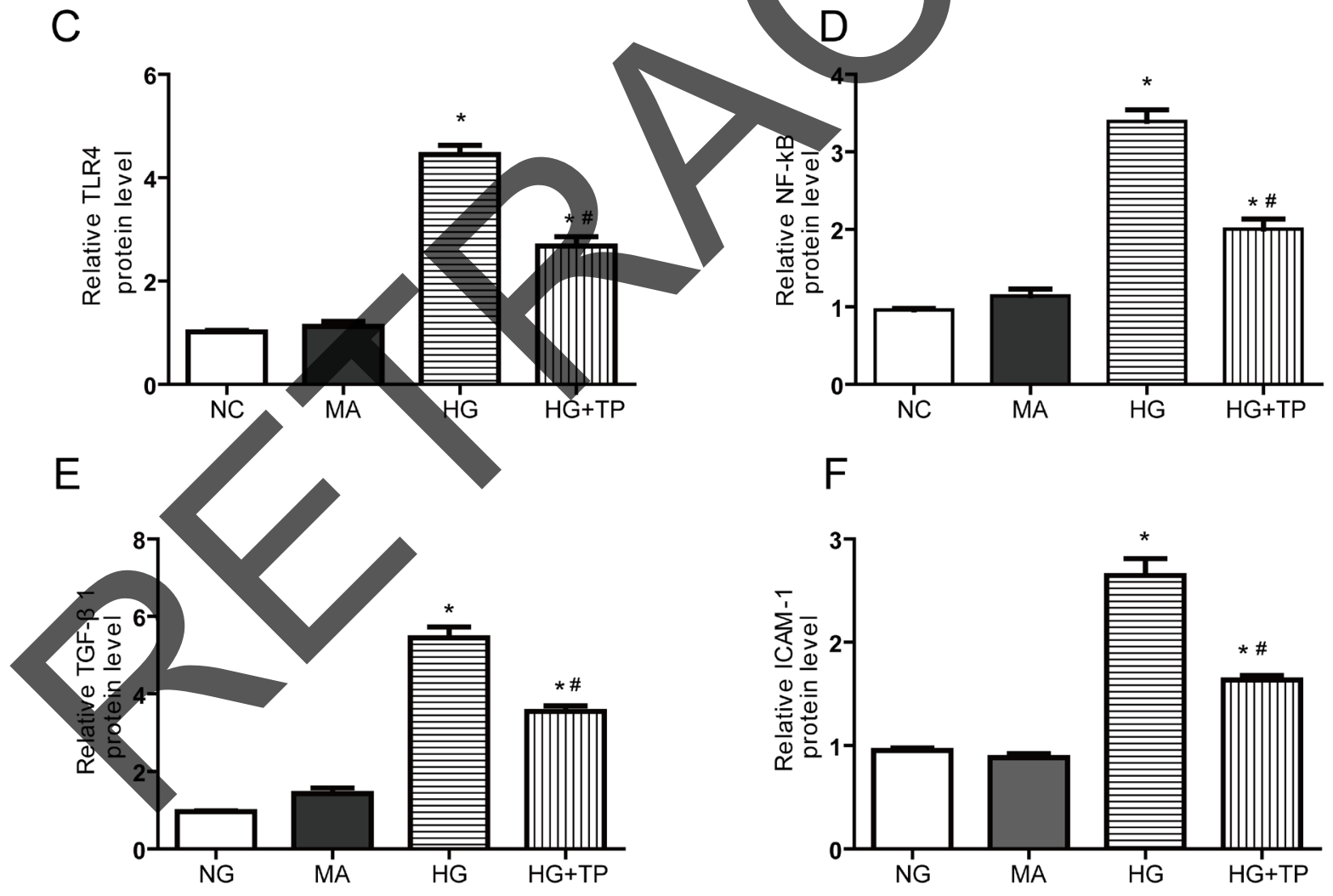

Figure 3: Triptolide reduces the inflammatory responses induced by high glucose concentrations in NRK-52E cells. A. The mRNA expression levels B. Representative western blotting. C.-F. Densitometric results determined via western blotting. NG, NRK-52E cells treated with normal glucose $(5.56 \mathrm{mmol} / \mathrm{L})$; MA, NRK-52E cells treated with normal glucose $(5.56 \mathrm{mmol} / \mathrm{L})+$ mannitol $(54.44 \mathrm{mmol} / \mathrm{L}) ; \mathrm{HG}$, NRK-52E cells treated with high glucose $(30 \mathrm{mmol} / \mathrm{L}) ; \mathrm{HG}+\mathrm{TP}, \mathrm{NRK}-52 \mathrm{E}$ cells treated with high glucose $+5 \mathrm{ng} / \mathrm{mL}$ triptolide. * $p<0.05$ versus $\mathrm{NG}$ group, $\# p<0.05$ versus $\mathrm{HG}$ group. 


\section{Triptolide attenuated renal histopathological changes in DN rats}

The renal tubules in DN rats exhibited signs of atrophy and luminal dilatation, as well as evidence of inflammatory cell infiltration in HE staining, compared to those in the NC rats. In the triptolide group, the degree of inflammatory cell infiltration was significantly reduced (Figure 1A). Masson staining results indicated that triptolide attenuates renal tubulointerstitial fibrosis (Figure 1B).

\section{Triptolide improved renal inflammation in DN rats}

The expression levels of TLR4, NF- $\mathrm{KB}$, TGF- $\beta 1$ and ICAM-1 were significantly increased in the DN group, compared with those in the $\mathrm{NC}$ group. After treated with triptolide, the situation was significantly improved (Figure $2 \mathrm{~A}-2 \mathrm{G})$.

\section{Triptolide attenuated high glucose-induced inflammation in NRK-52E cells}

The mRNA and protein expression levels of TLR4, NF- $\kappa$ B, TGF- $\beta 1$ and ICAM-1 were significantly higher in NRK-52E cells stimulated with high glucose concentrations for $48 \mathrm{~h}$ than those in Ne cells. Following $48 \mathrm{~h}$ triptolide, cytokines above were significantly decreased (Figure 3).

A

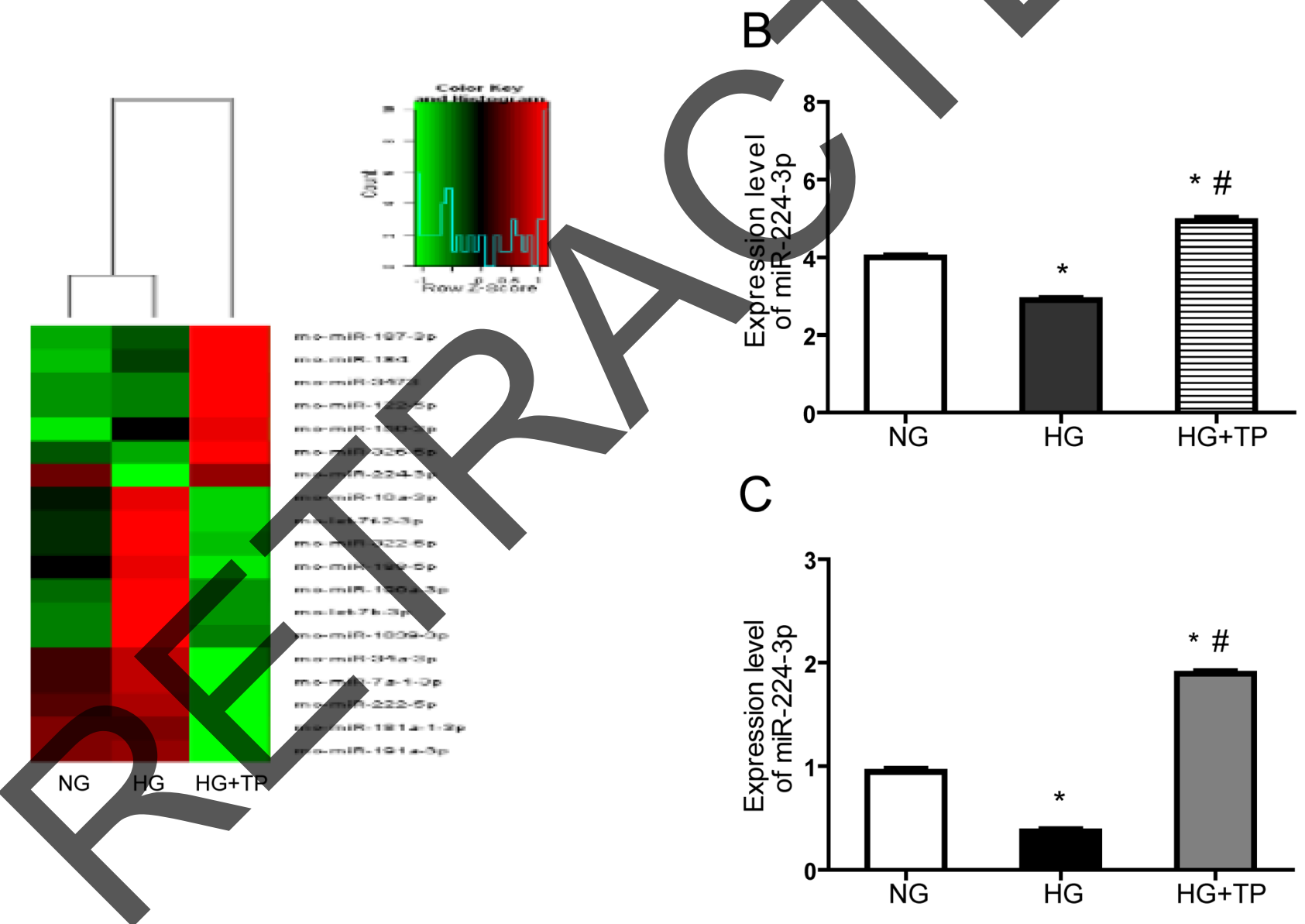

Figure 4: miRNA microarray analysis showed that the expression level of miR-224-3p was significantly different among the three groups. A. Hierarchical clustering of the normal and model groups. Differential miRNA expression profiles were observed. Red indicates upregulated miRNAs (higher expression), and green indicates downregulated miRNAs (lower expression); the aggregation tree is above the sample, and the miRNA aggregation tree is on the right. B. Statistical analysis: differential expression of miR224-3p in each group, according to the aggregation tree. C. Differential expression of miR-224-3p in each group. The level of miR-224-3p expression is expressed relative to that of U6 snRNA. NG, NRK-52E cells treated with normal glucose $(5.56 \mathrm{mmol} / \mathrm{L})$; HG, NRK-52E cells treated with high glucose $(30 \mathrm{mmol} / \mathrm{L})$; HG+TP, NRK-52E cells treated with high glucose $+5 \mathrm{ng} / \mathrm{mL}$ triptolide. ${ }^{*} p<0.05$ versus NG group, $\# p<0.05$ versus $\mathrm{HG}$ group. 
Table 1: Physical and biochemical parameters of the rats in different groups (mean \pm SD)

\begin{tabular}{|l|l|l|l|}
\hline & NC $(n=\mathbf{1 5})$ & $\mathbf{D N}(n=\mathbf{1 5})$ & $\mathbf{D N}+\mathbf{T P}(n=\mathbf{1 5})$ \\
\hline Blood glucose $(\mathrm{mmol} / \mathrm{L})$ & $6.0 \pm 0.2$ & $28.2 \pm 3.0 \mathrm{a}$ & $29.0 \pm 3.1 \mathrm{a}$ \\
\hline TC $(\mathrm{mmol} / \mathrm{L})$ & $3.7 \pm 1.2$ & $6.5 \pm 1.9^{*}$ & $6.2 \pm 2.0^{*}$ \\
\hline TG $(\mathrm{mmol} / \mathrm{L})$ & $1.5 \pm 1.2$ & $4.1 \pm 1.8^{*}$ & $3.8 \pm 1.4^{*}$ \\
\hline ALT $(\mathrm{mmol} / \mathrm{L})$ & $49.7 \pm 7.5$ & $55.1 \pm 5.1$ & $54.2 \pm 8.9$ \\
\hline AST $(\mathrm{mmol} / \mathrm{L})$ & $75.1 \pm 7.1$ & $79.4 \pm 6.4$ & $82.2 \pm 6.3$ \\
\hline BUN $(\mathrm{mmol} / \mathrm{L})$ & $6.9 \pm 2.0$ & $6.7 \pm 1.6$ & $6.8 \pm 1.2$ \\
\hline Scr $(\mathrm{mmol} / \mathrm{L})$ & $62.8 \pm 8.4$ & $61.3 \pm 7.3$ & $61.5 \pm 7.8$ \\
\hline 24-h urine protein $(\mathrm{mg} / 24 \mathrm{~h})$ & $45.7 \pm 14.5$ & $253.7 \pm 33.0^{*}$ & $119.0 \pm 22.0^{* \#}$ \\
\hline NAG & $12.3 \pm 4.1$ & $59.5 \pm 9.3^{*}$ & $29.4 \pm 7.2^{* *}$ \\
\hline KW/BW & $3.21 \pm 0.18$ & $6.78 \pm 0.48^{\mathrm{a} *}$ & $4.55 \pm 0.38^{* *}$ \\
\hline
\end{tabular}

TC: total cholesterol; TG: total triglycerides; ALT: alanine transaminase; AST. aspartate transaminase, BUN: blood urea nitrogen; Scr: serum creatinine; NC: normal control; DN: diabetic nephropathy rats without drug treatment; DN+TP: diabetic nephropathy rats treated with triptolide ( triptolide $200 \mu \mathrm{g} / \mathrm{kg} \cdot \mathrm{d}$ via gavage for 12 weeks) .*p $<0.05$ versus NC group, \#p $<$ 0.05 versus $\mathrm{DN}$ group.

\section{Effects of Triptolide on expression of miR-224-3p}

miRNA microarray analysis showed that miR224-3p expression was significantly decreased in the $\mathrm{HG}$ group, while returned to normal level in the $\mathrm{HG}+$ group (Figure 4A, 4B). We subsequently increased ou sample size and utilized qPCR to verify the differences in miR-224-3p expression in each group. Our results were consistent with the miRNA microarray analysis data (Figure 4C).

miR-224-3p overexpression reduced the levels of

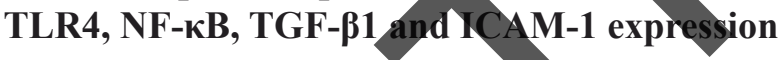

We ectopically expressed miR-224-3p in NRK-52E cells using miR-224-3p mimics (miR-224-3pm). After overexpression of miR-224-3pm, the levels of TLR4, NF$\kappa \mathrm{B}, \mathrm{TGF}-\beta 1$ and ICAM-1 expressions were significantly decreased compared to those of NC (Figure 5A-5F).

miR-224-3p downregulation reversed the antiinflammatory effects of triptolide

To determine the effects of miR-224-3p on the antiinflammatory effects of triptolide, we transfected miR224-3p inhibitors (miR-224-3pi) into NRK-52E cells. In contrast, following triptolide treatment, the expression levels of TLR4, NF- $\mathrm{B}$, TGF- $\beta 1$ and ICAM-1 were significantly increased (Figure 6), indicating that miR224-3p reversed the anti-inflammatory effects of triptolide.
niR-224-3p binding and suppression of TLR-4 expression in NRK-52E cells

To elucidate the molecular mechanisms underlying the anti-inflammatory effects of miR-224-3p, we next attempted to identify potential inflammatory pathway targets. TargetScan analysis predicted one putative miR224-3p binding site within the 3'UTR of TLR4 (Figure 7A). To determine if miR-224-3p effectively inhibits TLR4 expression through its interaction with the TLR4 3'UTR, we utilized a dual-luciferase reporter system. These results confirmed that TLR4 is a direct target of miR-224-3p and miR-224-3p can reduce the expression of TLR-4 in NRK52E cells (Figure 7B).

\section{The plasma miR-224-3p level was significantly decreased in DN patients}

Interestingly, we also detected the plasma levels of miR-224-3p via qPCR in three groups (NC, DM, and DN). The plasma level of miR-224-3p expression in the DM patients was similar to that of NC. However, the level of miR-224-3p in the DN patients was significantly lower.

\section{DISCUSSION}

$\mathrm{DN}$ is a type of glomerular disease mainly characterized by vascular damage. In recent years, renal tubular lesions and interstitial fibrosis have been found to be unique in terms of pathogenesis [21]. We found that renal tubules of DN rats exhibited pathological changes, such as partial epithelial cell brush border detachment, 
A

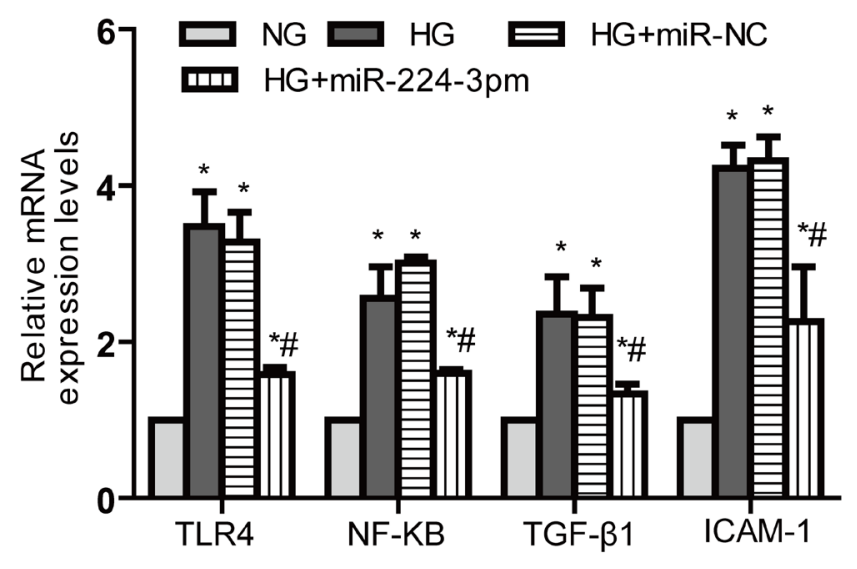

C
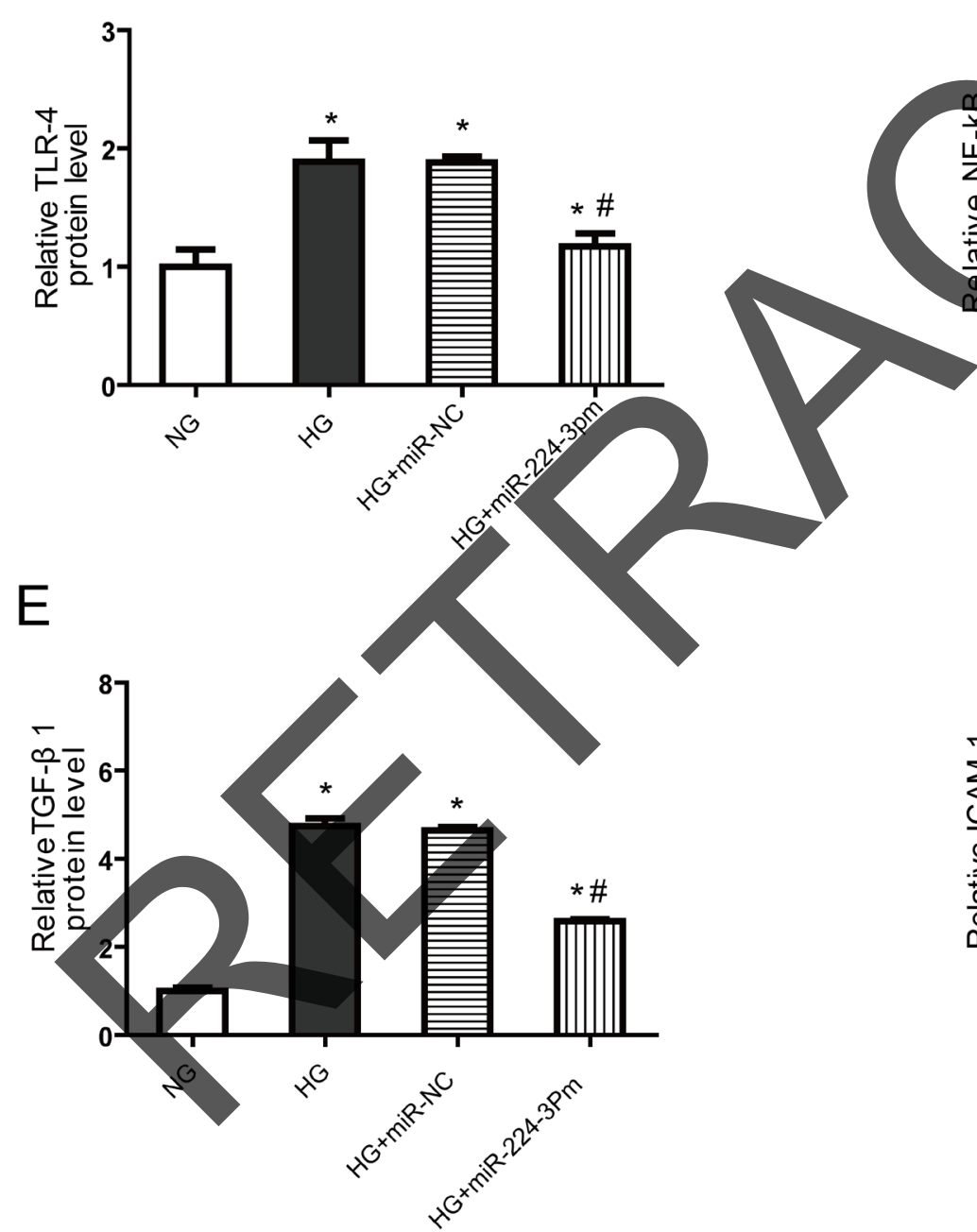

B

$\begin{array}{rcccc}\text { NG } & + & - & - & - \\ \text { HG } & - & + & + & + \\ \text { miR-NC } & - & - & + & - \\ \text { miR-224-3pm } & - & - & - & +\end{array}$

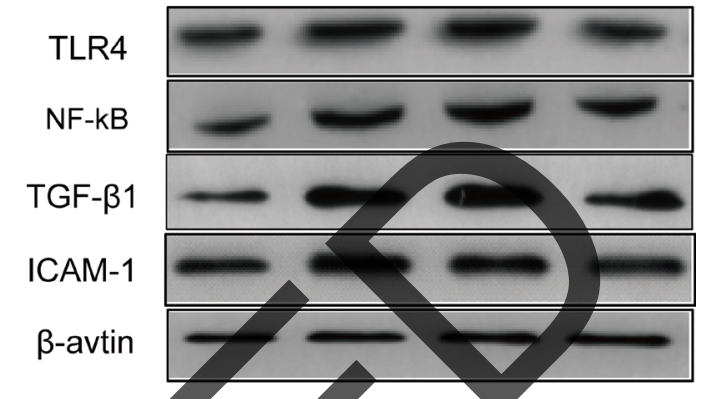

Figure 5: miR-224-3p overexpression reduces TLR4, NF-кB, TGF- $\beta 1$ and ICAM-1expression in NRK-52E cells transfected with an miR224-3p mimic. A. The mRNA expression B. Representative western blotting (C.-F. Densitometric results determined via western blotting. NG, NRK-52E cells treated with normal glucose $(5.56 \mathrm{mmol} / \mathrm{L}) ; \mathrm{HG}, \mathrm{NRK}-52 \mathrm{E}$ cells treated with high glucose ( $30 \mathrm{mmol} / \mathrm{L}) ; \mathrm{HG}+$ miR-NC, NRK-52E cells transfected with miR224-3p mimic control; HG+miR-3pm, NRK-52E cells transfected with miR224-3p mimic. * $p<0.05$ versus $\mathrm{NG}$ group, $\# p<0.05$ versus $\mathrm{HG}$ group. 
A

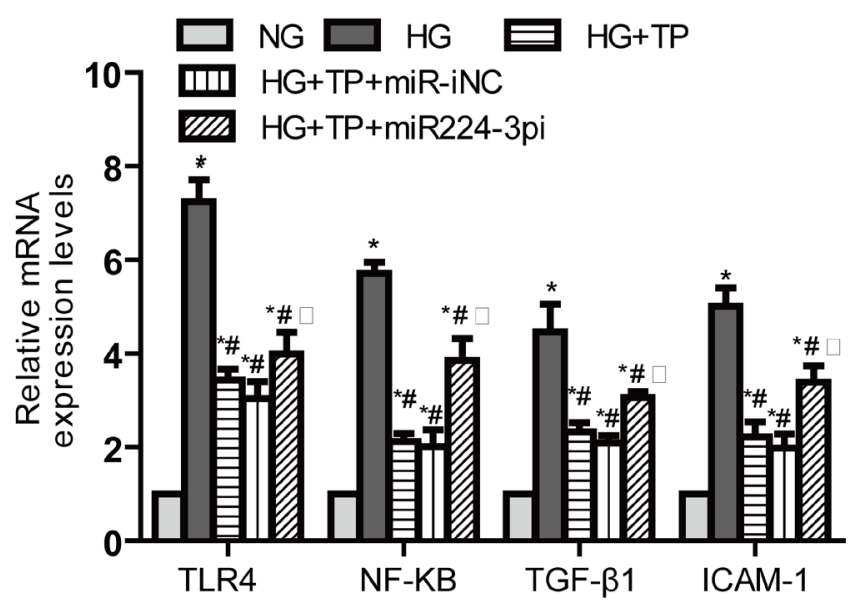

C
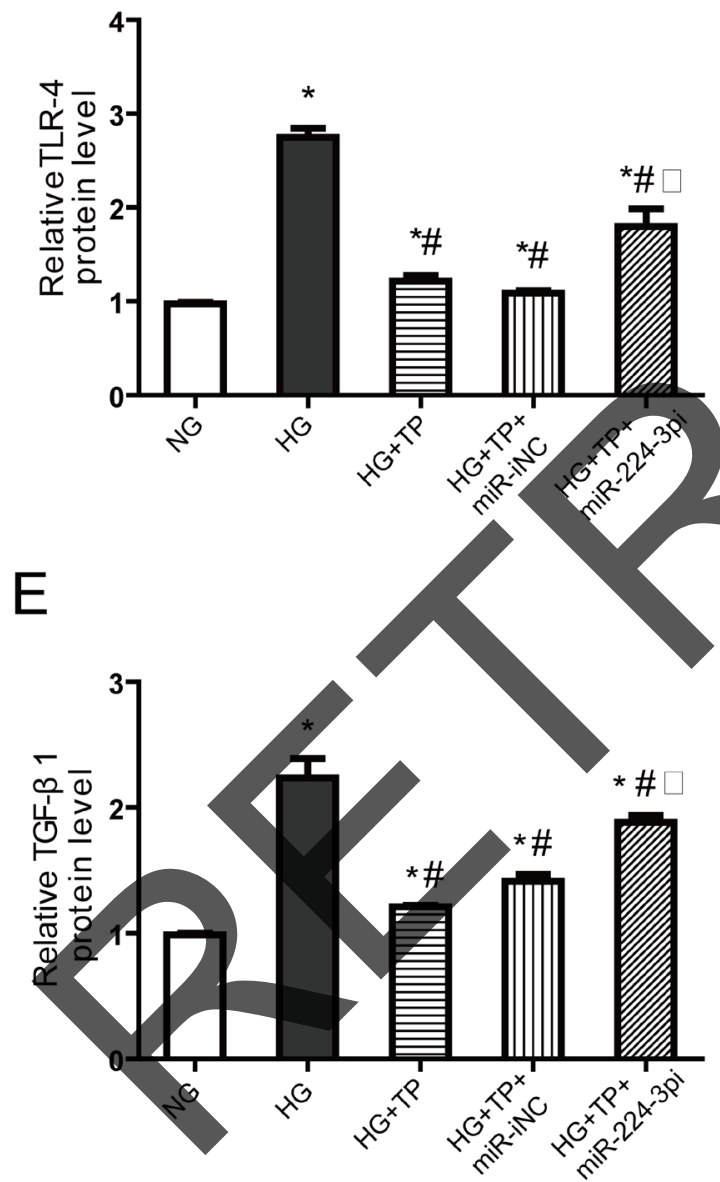

B

$\begin{array}{rccccc}\mathrm{NG} & + & - & - & - & - \\ \mathrm{HG} & - & + & + & + & + \\ \mathrm{TP} & - & - & + & + & + \\ \mathrm{miR}-\mathrm{NCi} & - & - & - & + & - \\ \mathrm{miR}-224-3 \mathrm{pi} & - & - & - & - & +\end{array}$

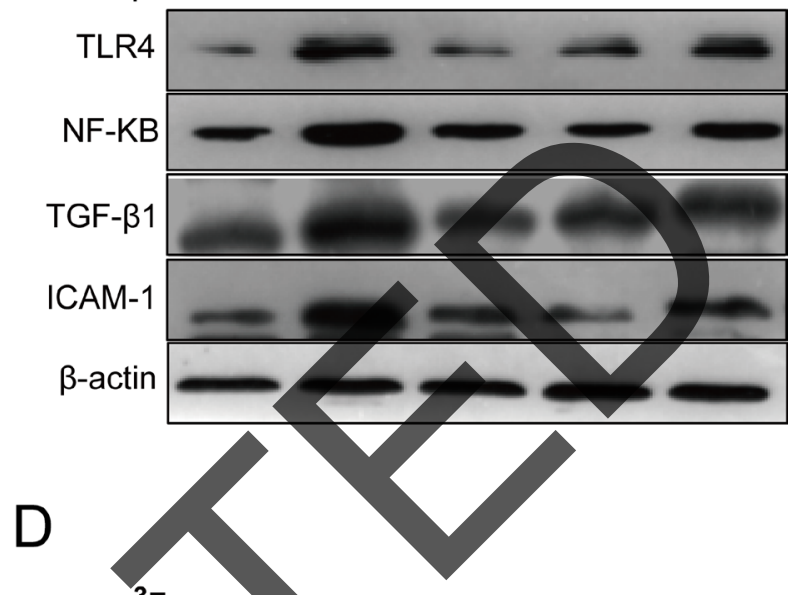

Figure 6: Downregulation of miR-224-3p expression reversed the anti-inflammatory effects of triptolide. NRK-52E cells were treated with triptolide alone or triptolide after transfection with an NC inhibitor and a miR-224 inhibitor. A. The mRNA expression levels B. Representative western blotting. (C-F) Densitometric results for TLR4, NF-kB, TGF- $\beta 1$ and ICAM-1, as determined via western blotting. NG, NRK-52E cells treated with normal glucose $(5.56 \mathrm{mmol} / \mathrm{L})$; HG, NRK-52E cells treated with high glucose $(30 \mathrm{mmol} / \mathrm{L})$; HG+TP,NRK-52E cells treated with high glucose $+5 \mathrm{ng} / \mathrm{mL}$ triptolide; HG+TP+miR-iNC, NRK-52E cells transfected with miR224-3p inhibitor control $+5 \mathrm{ng} / \mathrm{mL}$ triptolide; HG+TP+miR-3pi, NRK-52E cells transfected miR224-3p inhibitor $+5 \mathrm{ng} / \mathrm{mL}$ triptolide. ${ }^{*} p<0.05$ versus $\mathrm{NG}$ group, $\# p<0.05$ versus $\mathrm{HG}$ group, $\square p<0.05$ versus $\mathrm{HG}+\mathrm{TP}$ group. 
A

$\begin{array}{lccc}\text { TLR4 3' UTR } & \text { 5' } & \text { UAAAUUAAUCAUCAGCACCAUUU } & \text { 3' } \\ \text { rno-miR-224-3p } & \text { 3' } & \text { ACAUCAGUGAUCCCGUGGUAA } & \text { 5' } \\ \text { TLR4 3' UTR mut } & 5^{\prime} & \text { AGCATGGGCAATTTTGGAGCUUATC }\end{array}$

B

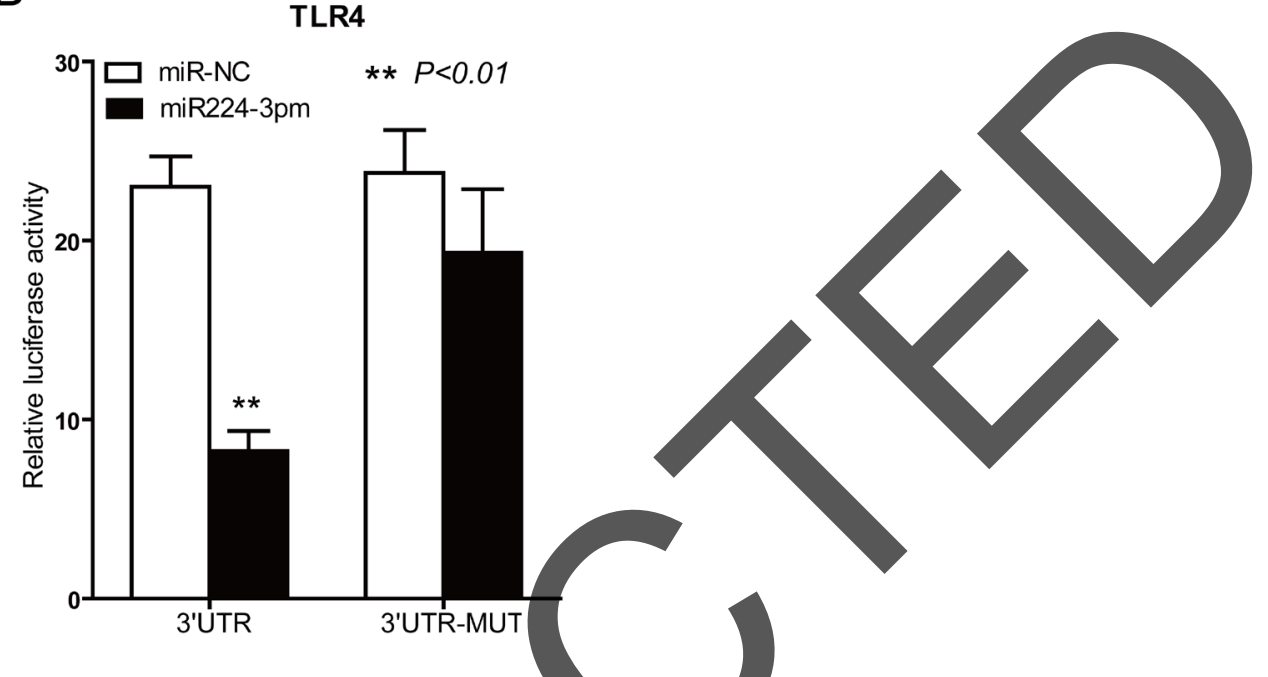

Figure 7: Target gene prediction and identification of miR-224-3p. A. Alignment of miR-224-3p with the predicted target region in the TLR4 3'UTR. A seven-nucleotide interaction sequence among the wild-type (wt) TLR4 3'UTR, miR-142-3p and the mutant TLR4 3'UTR construct is shown. B. Luciferase reporter assay using HEK-293 cells to show the direct interactions between miR-224-3p and the 3'UTR of TLR4. After 24 hours, the miR-224-3p mimic (10 nmol/L) reduced the ratio of Renilla-to-Firefly expression, but not when the 3'UTR bore 2 point mutations at the miR-224-3p binding site. C. TLR 4 protein expression levels in NRK-52E cells transfected with the miR224-3p mimic were examined via western blotting. (D) Densitometric results for TLR4, as determined via western blotting.

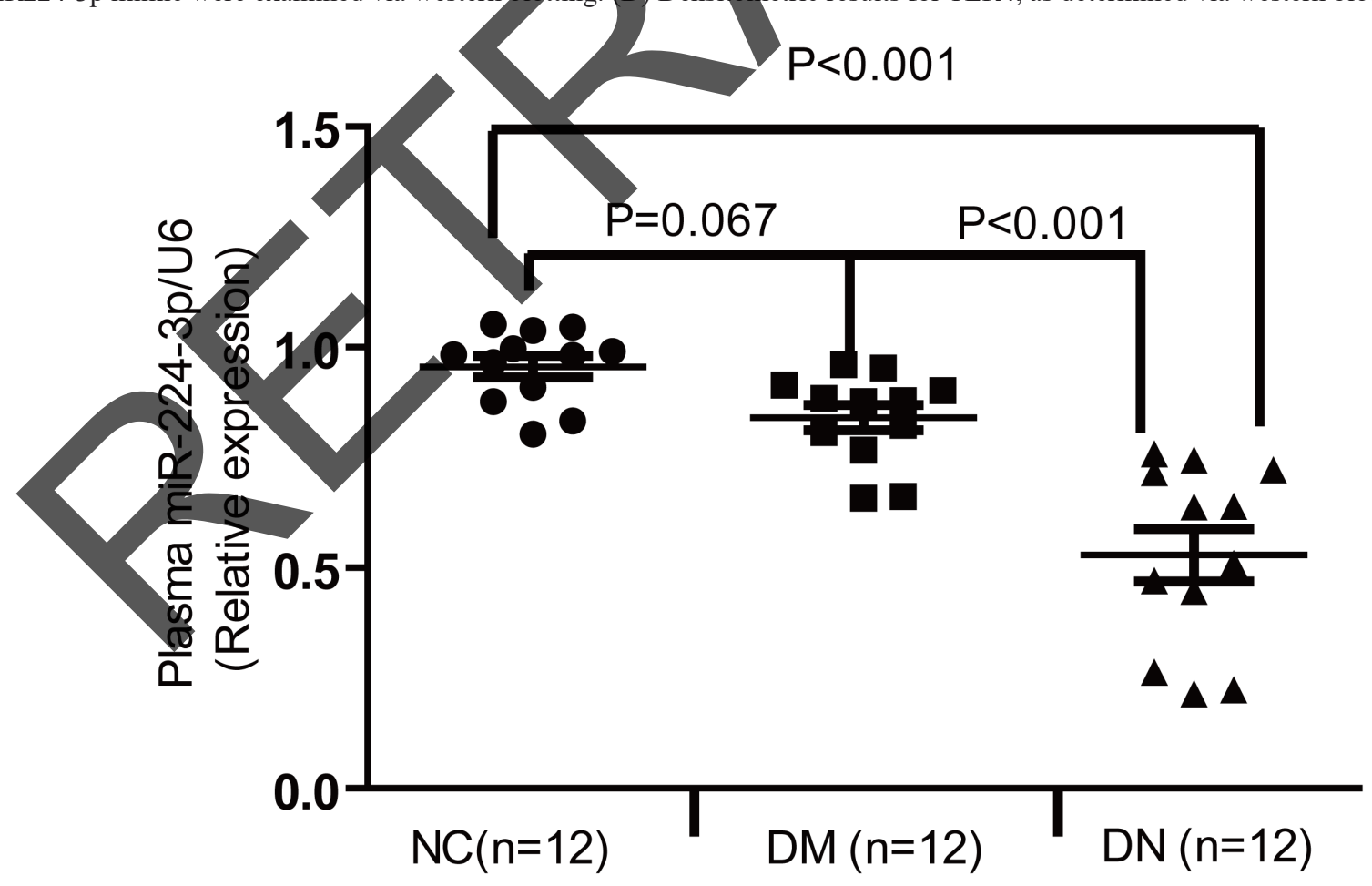

Figure 8: The plasma level of miR-224-3p was significantly decreased in DN patients. 
Table 2: Primers used for transcript quantification by qPCR

\begin{tabular}{|c|c|}
\hline Gene $^{\mathrm{a}}$ & Primer sequences $(5,-3,)^{b}$ \\
\hline Hs/Rs miR-224-3p Stemloop & $\begin{array}{l}\text { GTCGTATCCAGTGCAGGGTCCGAGG } \\
\text { TATTCGCACTGGATACGACTGTAGT }\end{array}$ \\
\hline Rs miR-224-3p F & GGTCCAAATGGTGCCCTAGTG \\
\hline Hs miR-224-3p F & GGTCCAAAATGGTGCCCTAGTGAC \\
\hline Universal primer $\mathrm{R}$ & CCAGTGCAGGGTCCGAGGT \\
\hline Hs/Rs RNU6 F & CTCGCTTCGGCAGCACATATACT \\
\hline Hs/Rs RNU6 R & ACGCTTCACGAATTTGCGTGTC \\
\hline Rs TLR4 F & CCGCTCTGGCATCATCTTCA \\
\hline Rs TLR4 R & TCCC \\
\hline Rs NF-Kb F & TGTCA \\
\hline Rs NF-Kb R & CCTCQ \\
\hline Rs TGF- $\beta 1 \mathrm{~F}$ & CCTCC \\
\hline Rs TGF- $\beta 1 \mathrm{R}$ & CAGCCG \\
\hline Rs ICAM-1 F & $\mathrm{CQ}$ \\
\hline Rs ICAM-1 R & \\
\hline Rs GAPDH F & GCACAG \\
\hline Rs GAPDH R & ACTCCACGACAT \\
\hline
\end{tabular}

as well as vacuolization and granular degeneration. Inflammatory cell infiltration was also noted.

More and more researchers have concluded that DN is a type of autoimmune disease [22]. Renal cells in the settings of hyperglycemia and hemodynamic alterations can produce many types of inflammatory cytokines, which trigger an inflammatory cascade reaction [23], resulting in the development of DN.

TLRs are important factors in inflammatory reactions, served as a bridge linking innate and acquired immunity [24]. TLR4 expressed on the surface of a variety of cells is one of the best studied TLR subtypes. Recently, TLR4 was reported to express in renal tubular epithelial cells in diabetic rats. TLR4 activation induces production of cytokines and chemokines and participates in various immune and inflammatory reactions $[25,26]$. TLR4 activates the NF- $\kappa \mathrm{B}$ signaling pathway, resulting in inflammatory factor released. After NF- $\kappa \mathrm{B}$ activation, IL-1 $\beta$, TGF- $\beta 1$ and TNF- $\alpha$ transcriptions and translations are initiated, which then activates the Smad signaling pathway. NF- $\kappa \mathrm{B}$ also stimulates the transcription of several fiber-related factors, such as ICAM-1 and VCAM1 [27], and promotes the proliferation and differentiation of renal tubular cells.

Triptolide has strong anti-inflammatory effects. In line with our study, Triptolide inhibits the expression of various cytokines and adhesion molecules, which inhibits the activation of inflammatory cells, such as neutrophils and macrophages, thereby inhibiting inflammation $[28,29]$. In this study, Triptolide reduces renal tubular epithelial cell vacuolization and granular degeneration, as well as inflammatory cell infiltration, and improves renal tubular expansion and contraction via downregulation of the expression of TLR $4, N F-\kappa B$, TGF- $\beta 1$ and ICAM- 1 in vivo and in vitro. This might be one of the mechanisms underlying the effects of triptolide on renal tubular interstitial injury.

miRNAs play an important role in cell proliferation, growth, differentiation and apoptosis [30,31]. Several important miRNAs were found to highly express in 
Table 3: Characteristics of the Study Population

\begin{tabular}{|c|c|c|c|}
\hline Variables & NC & DM & DN \\
\hline Patient number(n) & 12 & 12 & 12 \\
\hline Gender(F/M) & $6 / 6$ & $7 / 5$ & $6 / 6$ \\
\hline Age(year) & $52.4 \pm 10.3$ & $51.7 \pm 12.1$ & $57.3 \pm 12.7$ \\
\hline Course of disease(year) & & $6.7 \pm 3.5$ & $13.8 \pm 4.7$ \\
\hline $\mathrm{BMI}\left(\mathrm{Kg} / \mathrm{m}^{2}\right)$ & $25.9 \pm 1.8$ & $26.2 \pm 2.3$ & $26.9 \pm 2.4$ \\
\hline High pressure (mmHg) & $130 \pm 10$ & $134 \pm 12$ & \\
\hline Low pressure(mmHg) & $81 \pm 11$ & $83 \pm 16$ & \\
\hline $\mathrm{HbA}_{1 \mathrm{c}}(\%)$ & $5.2 \pm 0.8$ & $9.6 \pm 1.4^{*}$ & \\
\hline Blood Glucose $(\mathrm{mmol} / \mathrm{L})$ & $4.9 \pm 1.1$ & $9.9 \pm 2.1 *$ & \\
\hline $24 \mathrm{~h}-\mathrm{UTP}(\mathrm{g} / 24 \mathrm{~h})$ & & $0.1 \pm 0$. & $0.96^{\#}$ \\
\hline $\operatorname{Scr}(\mathrm{mmol} / \mathrm{L})$ & $47 \pm 6.7$ & $58.8 \pm 8.1$ & $67.5 \pm 18.3$ \\
\hline $\mathrm{TG}(\mathrm{mmol} / \mathrm{L})$ & $1.64 \pm 0.41$ & & $1.97 \pm 0.65$ \\
\hline $\mathrm{LDL}(\mathrm{mmol} / \mathrm{L})$ & $2.87 \pm 0.34$ & & $3.63 \pm 0.59$ \\
\hline
\end{tabular}

$\mathrm{NC}=$ non-Diabetes, $\mathrm{DM}=$ Diabetes, $\mathrm{DN}=$ Diabetic nephropath

*Indicated control with $\mathrm{NC}, \mathrm{P}<0.05$

\# Indicated control with DM,P $<0.01$

renal tissue. Using miRNA gene chip technology, high expression levels of mir-192, miR-194, miRNA-204, miRNA-215, miRNA-217, miRNA-27a, mirna-27b and miRNA-29c have been noted in kidney tissues [32-34]. Abnormal miRNA expression may lead to the development of renal disease. In this study, we analyzed the levels of miRNA expression using miRNA microarray technology. Our results showed that miR-224-3p expression was significantly downregulated in the high-glucose group, while triptolide reversed the inhibition of miR-224-3p. After the cells were transfected with miR-224-3p mimics, the expressions of TLR $4, \mathrm{NF}-\kappa \mathrm{B}, \mathrm{TGF}-\beta 1, \mathrm{ICAM}-1$ and other inflammatory factors were decreased significantly, indicating that miR-224-3p mediated the decrease in inflammation in DN by triptolide.

In conclusion, miR-224-3p expression was decreased in DN. Triptolide upregulated miR-224-3p expression, which resulted in decreased TLR4, NF$\kappa \mathrm{B}, \mathrm{TGF}-\beta 1$ and ICAM-1 expressions and reduced inflammation. This may represent the novel mechanism by which triptolide improves DN.

\section{MATERIALS AND METHODS}

\section{Animals}

SD male rats were purchased from HFK Bioscience Company (Beijing, China). All experimental rats were maintained under specific pathogen-free conditions in the animal facility of Tianjin Medical University (China) and used for experimentation at $6 \mathrm{wk}$. The Tianjin Medical University Experimental Animal Ethics Committee approved all animal procedures.

Rats were randomly assigned to 3 groups. The rats were fed a standard diet ( $8 \%$ fat) or a high-fat diet (HFD) containing $40 \%$ fat for 8 weeks. The HFD animals were intraperitoneally injected with a single dose of STZ (30 $\mathrm{mg} / \mathrm{kg}$ ) in $50 \mathrm{mM}$ citrate buffer ( $\mathrm{pH} 4.0)$, while the control animals received an equal volume of citrate buffer. The hyperglycemia noted in the HFD rats after STZ injection was not due to declining beta-cell function [35]. Animals with blood glucose levels $\geq 16.7 \mathrm{mmol} / \mathrm{L}$ were deemed diabetes. $24 \mathrm{~h}$ UMA levels $\geq 30 \mathrm{mg}$ were considered to 
have DN.

The animals were divided into the following 3 groups: NC, DN and DN + Triptolide ( triptolide $200 \mu \mathrm{g} /$ $\mathrm{kg} \cdot \mathrm{d}$ via gavage for 12 weeks).

\section{Cell culture and treatment}

Rat kidney tubular epithelial cells (NRK52E cells; American Type Culture Collection,

Rockville, MD, USA) were maintained in DMEM containing $10 \%$ FBS, penicillin $(200 \mathrm{U} / \mathrm{mL})$, and streptomycin $(200 \mu \mathrm{g} / \mathrm{mL})$ (Gibco BRL, Grand Island, $\mathrm{NY}$, USA) at $37^{\circ} \mathrm{C}$ in a humidified incubator containing $5 \% \mathrm{CO} 2$. The cells were divided into (1) the NG group incubated in DMEM containing $5.56 \mathrm{mmol} / \mathrm{L}$ glucose, (2) the MA group incubated in DMEM containing 5.56 $\mathrm{mmol} / \mathrm{L}$ glucose and $54.44 \mathrm{mmol} / \mathrm{L}$ mannitol, (3) the HG group incubated in DMEM containing $25 \mathrm{mM}$ glucose, and (4) the HG+TP group incubated with $5 \mathrm{ng} / \mathrm{mL}$ triptolide in DMEM containing $25 \mathrm{mM}$ glucose for $24 \mathrm{~h}$.

\section{Gene chip technology analysis}

Total RNA was isolated using TRIzol (Invitrogen, USA) and purified with an RNeasy mini kit (QIAGEN, GER), according to manufacturer's instructions. Shanghai Biotechnology Co., Ltd conducted the MicroRNA microarray gene expression experiments and data analysis

\section{Transfection of the miRNA mimic and inhibitors \\ An miR224-3p mimic,} and appropriate negative controls (NC) of the miRNA inhibitor (miR-iNC) and miRNA mimic (miR-NC) were purchased from GenePharma (Sunzhou, China) and transfected at final concentrations ranging from 50$100 \mathrm{nM}$ using Lipofectamine 2000 transfection reagent (Invitrogen, USA), in accordance with the manufacturer's recommendations. The transfected cells were growtharrested via overnight incubation with serum-free medium prior to incubation with $25 \mathrm{mM}$ glucose for $48 \mathrm{~h}$.

Luciferase reporter assay for miR224-3p binding the TLR4 3 -UTR

A luciferase reporter assay was conducted using a Dual-Luciferase Reporter Assay System (Promega, USA), according to the manufacturer's instructions. 293T cells $\left(1.5 \times 10^{4} /\right.$ well $)$ were seeded into 96-well plates. After 12 $\mathrm{h}$, the cells were transiently co-transfected with $0.1 \mu \mathrm{g} /$ well pRL-TK plasmid (Promega) containing a Renilla luciferase gene for internal normalization and various constructs containing pMIR-TLR4 and pMIR-TLR4-mut. Cells were lysed and assayed for luciferase activity $36 \mathrm{~h}$ after transfection. One hundred microliters of protein extracts were analyzed in a luminometer. All experiments were performed at least three times.

\section{Histological analysis}

Kidney tissues were fixed in formalin, embedded in paraffin, and cut into $5 \mu \mathrm{m}$ thick sections. The sections were stained with a hematoxylin and eosin (HE) staining kit (Baibo Biotechnology Co., Ltd., Shandong, China), periodic acid-Schiff (PAS) staining kit and Masson's trichrome (MT) staining kit (Nanjing Jiancheng Bioengineering Institute, Jiangsu, China) according to the manufacturer's protocols. For each slide, 10 randomly selected non-overlapping fields of renal cortex without glomeruli and large vessels were measured, and the averages for each group were analyzed.

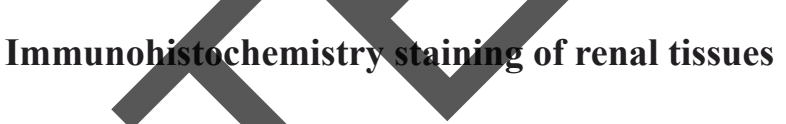

Formalin-fixed, paraffin-embedded sections $(4 \mu \mathrm{m}$ ick) were deparaffinized by xylene and hydrated by graded ethanol. Heat-induced antigen retrieval was conducted at $95{ }^{\circ} \mathrm{C}$ by microwave in $10 \mathrm{mmol} / \mathrm{L}$ sodium citrate buffer ( $\mathrm{pH}$ 6.0) for $5 \mathrm{~min}$. Then, the sections were blocked with $5 \%$ BSA for $30 \mathrm{~min}$ and incubated overnight at $4^{\circ} \mathrm{C}$ with the following antibodies diluted with PBS: anti-NF- $\mathrm{KB}$ (Cell Signaling Technology, 1:100), antiTGF-31 (Abcam, 1:200), anti-ICAM-1 (Abcam, 1:100) and anti-VCAM-1 (Abcam, 1:100). After washed three times in PBS, the sections were incubated for 45 min with the appropriate secondary antibody. The sections were subsequently visualized with a Diaminobenzidine (DAB) kit and counterstained with hematoxylin.

\section{RNA isolation and analysis with qPCR}

Total RNA was isolated by using Trizol reagent (Invitrogen, Carlsbad, CA, USA). This total RNA $(1 \mu \mathrm{g})$ was then used for cDNA synthesis with a Transcriptor First Stand cDNA Synthesis Kit (Roche, IN, USA). Realtime quantitative PCR (qPCR) was performed using a quantitative SYBR Green PCR kit (TaKaRa, Dalian, China). The SYBR Green fluorescence absorption values in each tube were detected at the end of each cycle. miRNA and RNA expression levels were normalized to those of a specific small nuclear RNA (RNU6) or housekeeping gene (GAPDH). All primers are listed in Table 2.

\section{Western blot analysis}

The primary antibodies and their dilutions used were as follows: NF-kB p65 (1:1000), TGF- $\beta 1$ (1:2000), 
ICAM-1 (1:2000), VCAM-1 (1:1000) and $\beta$-actin (SigmaAldrich, 1:1000). Following incubation with horseradish peroxidase-coupled secondary anti-mouse/rabbit (Tianjin Sungene Biotech), protein bands were visualized using ECL Blotting Detection Reagents (NCI4106, Thermo Pierce ECL). The blots were quantified via densitometry using Image J software.

\section{Patients and specimens}

The participants were recruited in our hospital from January to July 2015 in Tianjin, China (Table 3). DN was diagnosed based on a urinary albumin excretion ratio greater than or equal to $30 \mathrm{mg} / 24 \mathrm{~h}$, a serum creatinine greater than $167 \mu \mathrm{mol} / \mathrm{L}$ or a blood urea nitrogen greater than $7.8 \mathrm{mmol} / \mathrm{L}$. Individuals were excluded if they were pregnant or lactating, had type 1 diabetes or another type of diabetes, had another secondary renal disease or renal dysfunction caused by primary renal disease or hypertension, had active liver disease or abnormal liver function, had a urinary tract infection or had severe hypertension. Serum and urine samples were collected from 12 patients. The control group is comprised of 12 healthy subjects.

\section{Statistical analysis}

All data are expressed as the mean \pm standard erro (SE). Comparisons between two parameters were analyzed by Student's unpaired $t$-test. $P<0.05$ was considered statistically significant. Between-group differences in latency were analyzed via analysis of variance for repeated measurements (ANOVAR), followed by Fisher's post hoc test for all groups.

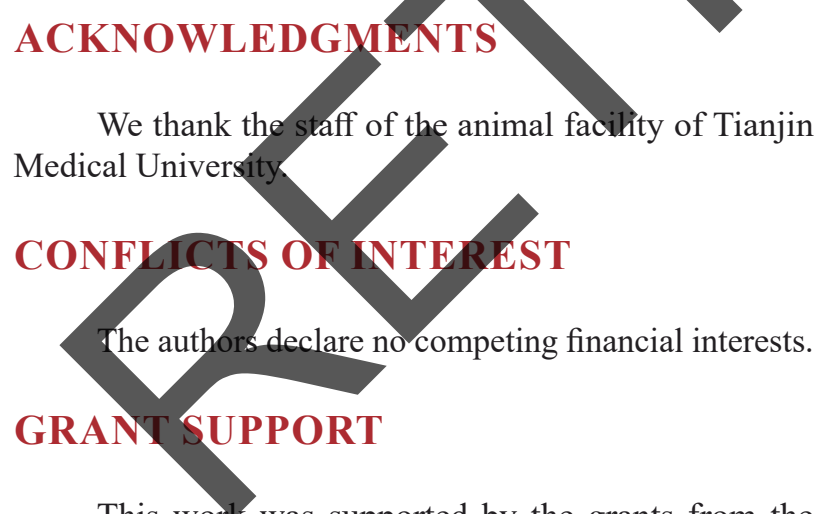

This work was supported by the grants from the National Natural Science Foundation of China (No. 81470187, 81273915, 81072922 to Chen L.M.).

\section{REFERENCES}

1. Gross J L, De Azevedo M J, Silveiro S P, Canani L H, Caramori M L, Zelmanovitz T. Diabetic nephropathy: diagnosis, prevention, and treatment. Diabetes Care.2005;28:164-76.

2. Reutens A T, Atkins R C. Epidemiology of diabetic nephropathy. Contrib Nephrol.2011;170:1-7.

3. Park C W. Diabetic kidney disease: from epidemiology to clinical perspectives. Diabetes Metab J.2014;38:252-60.

4. Luis-Rodriguez D, Martinez-Castelao A, Gorriz J L, DeAlvaro F, Navarro-Gonzalez J F. Pathophysiological role and therapeutic implications of inflammation in diabetic nephropathy. World J Diabetes.2012;3:7-18.

5. Mudaliar H, Pollock C, Komala M G, Chadban S, Wu H, Panchapakesan U. The role of Toll-like receptor proteins (TLR) 2 and 4 in mediating inflammation in proximal tubules. Am J Physiol Renal Physiol.2013;305:F143-54.

6. Mezzano S, Aros C, Droguett A, Burgos M E, Ardiles L, Flores C, Schneider H, Ruiz-Ortega M, Egido J. NF-kappaB activation and overexpression of regulated genes in human diabetic nephropathy. Nephrol Dial Transplant. 2004;19:2505-

7. Lin $\mathrm{M}$, Yiu WH, Wu H J, Chan L Y, Leung J C, Au W S, Chan K W, Lai K N, Tang S C. Toll-like receptor 4 promotes tubular inflammation in diabetic nephropathy. $\mathrm{J}$ Am Soc Nephrol.2012;23:86-102.

Fried L F, Emanuele N, Zhang J H, Brophy M, Conner T A, Duckworth W, Leehey D J, Mccullough P A, O'Connor T, Palevsky P M, Reilly R F, Seliger S L, Warren S R, et al. Combined angiotensin inhibition for the treatment of diabetic nephropathy. N Engl J Med.2013;369:1892-903.

9. Packham D K, Wolfe R, Reutens A T, Berl T, Heerspink H L, Rohde R, Ivory S, Lewis J, Raz I, Wiegmann T B, Chan J C, De Zeeuw D, Lewis E J, et al. Sulodexide fails to demonstrate renoprotection in overt type 2 diabetic nephropathy. J Am Soc Nephrol.2012;23:123-30.

10. Ismail-Beigi F, Craven T, Banerji M A, Basile J, Calles J, Cohen R M, Cuddihy R, Cushman W C, Genuth S, Jr Grimm R H, Hamilton B P, Hoogwerf B, Karl D, et al. Effect of intensive treatment of hyperglycaemia on microvascular outcomes in type 2 diabetes: an analysis of the ACCORD randomised trial. Lancet.2010;376:419-30.

11. Ma J, Xu L, Dong J, Wei H, Zhi Y, Ma X, Zhang W. Effects of zishentongluo in patients with early-stage diabetic nephropathy. Am J Chin Med.2013;41:333-40.

12. Kitada M, Kume S, Imaizumi N, Koya D. Resveratrol improves oxidative stress and protects against diabetic nephropathy through normalization of Mn-SOD dysfunction in AMPK/SIRT1-independent pathway. Diabetes.2011;60:634-43.

13. Ma R, Liu L, Liu X, Wang Y, Jiang W, Xu L. Triptolide markedly attenuates albuminuria and podocyte injury in an animal model of diabetic nephropathy. Exp Ther Med.2013;6:649-56.

14. Gao Q, Shen W, Qin W, Zheng C, Zhang M, Zeng C, Wang $\mathrm{S}$, Wang J, Zhu X, Liu Z. Treatment of $\mathrm{db} / \mathrm{db}$ diabetic mice with triptolide: a novel therapy for diabetic nephropathy. 
Nephrol Dial Transplant.2010;25:3539-47.

15. Wen H L, Liang Z S, Zhang R, Yang K. Anti-inflammatory effects of triptolide improve left ventricular function in a rat model of diabetic cardiomyopathy. Cardiovasc Diabetol.2013;12:50.

16. Ma Z J, Zhang X N, Li L, Yang W, Wang S S, Guo X, Sun $\mathrm{P}$, Chen L M. Tripterygium Glycosides Tablet Ameliorates Renal Tubulointerstitial Fibrosis via the Toll-Like Receptor 4/Nuclear Factor Kappa B Signaling Pathway in HighFat Diet Fed and Streptozotocin-Induced Diabetic Rats. J Diabetes Res.2015;2015:390428.

17. Huntzinger E, Izaurralde E. Gene silencing by microRNAs: contributions of translational repression and mRNA decay. Nat Rev Genet.2011;12:99-110.

18. Krupa A, Jenkins R, Luo D D, Lewis A, Phillips A, Fraser D. Loss of MicroRNA-192 promotes fibrogenesis in diabetic nephropathy. J Am Soc Nephrol.2010;21:438-47.

19. Wang Q, Wang Y, Minto A W, Wang J, Shi Q, Li X, Quigg R J. MicroRNA-377 is up-regulated and can lead to increased fibronectin production in diabetic nephropathy. FASEB J.2008;22:4126-35.

20. Putta S, Lanting L, Sun G, Lawson G, Kato M, Natarajan R. Inhibiting microRNA-192 ameliorates renal fibrosis in diabetic nephropathy. J Am Soc Nephrol.2012;23:458-69.

21. Tang S C, Leung J C, Lai K N. Diabetic tubulopathy: an emerging entity. Contrib Nephrol.2011;170:124-34.

22. Duran-Salgado M B, Rubio-Guerra A Diabetic nephropathy and inflammation. World Diabetes.2014;5:393-98.

23. Navarro-Gonzalez J F, Mora-Fernandez C. The role of inflammatory cytokines in diabetic nephropathy. J Am Soc Nephrol.2008;19:433-42.

24. Jialal I, Kaur H. The Role Diabetes-Induced Inflammation: Implications for Vascular Complications. Curr Diab Rep.2012

25. Lin M, Yiu W H, Li R X, Wu H J, Wong D W, Chan L Y, Leung J C, Lai KN, Tang S C. The TLR4 antagonist CRX526 protects against advaneed diabetic nephropathy. Kidney Int.2013;83:887-900.

26. Kaur H,Chien A, Jiala1 I. Hyperglycemia induces Toll like receptor 4 expression and activity in mouse mesangial cells: relevance to diabetic nephropathy. Am J Physiol Renal Physiol.2012;303:F1145-50.

27. Kuhad A, Chopra K. Attenuation of diabetic nephropathy by tocotrienol: involvement of NFkB signaling pathway. Life Sci.2009;84:296-301.

28. Zhang N, Xu Y J, Zhang Z X. [Regulatory function of nuclear factor kappa B on lymphocyte proliferation and apoptosis in bronchial asthmatic rats and effect of triptolide on the regulation]. Zhongguo Zhong Xi Yi Jie He Za Zhi.2004;24:435-38.

29. Liu Q, Chen T, Chen G, Li N, Wang J, Ma P, Cao X. Immunosuppressant triptolide inhibits dendritic cellmediated chemoattraction of neutrophils and T cells through inhibiting Stat3 phosphorylation and NF-kappaB activation. Biochem Biophys Res Commun.2006;345:1122-30.

30. Bartel D P. MicroRNAs: target recognition and regulatory functions. Cell.2009;136:215-33.

31. Sayed D, Abdellatif M. MicroRNAs in development and disease. Physiol Rev.2011;91:827-87.

32. Li J Y, Yong T Y, Michael M Z, Gleadle J M. Review: The role of microRNAs in kidney disease. Nephrology (Carlton).2010;15:599-608.

33. Lu X, Fan Q, Xu L, Li L, Yue Y, Xu Y, Su Y, Zhang D, Wang L. Ursolic acid attenuates diabetic mesangial cell injury through the up-regulation of autophagy via miRNA-21/PTEN/Akt/mTOR suppression. PLoS One.2015;10:e117400.

34. Zhang Z, Luo X, Ding S, Chen J, Chen T, Chen X, Zha H, Yao L, He X, Peng H. MicroRNA-451 regulates p38 MAPK signaling by targeting of Ywhaz and suppresses the mesangial hypertrophy in early diabetie nephropathy. FEBS Lett.2012;586:20-26.

35. Kong L L, Wu H, Cui W P, Zhou W H, Luo P, Sun J, Yuan H, Miao LN.Advances in murine models of diabetic nepbropathy. J Diabetes Res.2013;2013:797548. 